\title{
Quantitative Effects of Vehicle Parameters on Fuel Consumption for Heavy-Duty Vehicle
}

\section{Lijuan Wang, Kenneth Kelly, Kevin Walkowicz, and Adam Duran}

National Renewable Energy Laboratory

CITATION: Wang, L., Kelly, K., Walkowicz, K., and Duran, A., "Quantitative Effects of Vehicle Parameters on Fuel Consumption for Heavy-Duty Vehicle," SAE Technical Paper 2015-01-2773, 2015, doi:10.4271/2015-01-2773.

Copyright (C) 2015 SAE International

\begin{abstract}
The National Renewable Energy Laboratory's (NREL's) Fleet Test and Evaluations team recently conducted chassis dynamometer tests of a class 8 conventional regional delivery truck over the Heavy Heavy-Duty Diesel Truck (HHDDT), West Virginia University City (WVU City), and Composite International Truck Local and Commuter Cycle (CILCC) drive cycles. A quantitative study analyzed the impacts of various factors on fuel consumption (FC) and fuel economy (FE) by modeling and simulating the truck using NREL's Future Automotive Systems Technology Simulator (FASTSim). Factors included vehicle weight and the coefficients of rolling resistance and aerodynamic drag. Simulation results from a single parametric study revealed that FC was approximately a linear function of the weight, coefficient of aerodynamic drag, and rolling resistance over various drive cycles. The study of the impact of two technologies on FE suggested that, depending on the circumstances, it may be more cost effective to reduce one parameter (such as coefficient of aerodynamic drag) to increase fuel economy, or it may be more beneficial to reduce another (such as the coefficient of rolling resistance). It also provided a convenient way to estimate FE by interpolating within the parameter values and extrapolating outside of them. The simulation results indicated that FC could be reduced from $38.70 \mathrm{~L} / 100 \mathrm{~km}, 50.72 \mathrm{~L} / 100 \mathrm{~km}$, and $38.42 \mathrm{~L} / 100 \mathrm{~km}$ in the baseline truck to $26.78 \mathrm{~L} / 100 \mathrm{~km}, 43.14 \mathrm{~L} / 100 \mathrm{~km}$ and $29.84 \mathrm{~L} / 100 \mathrm{~km}$ over the HHDDT, WVU City and CILCC drive cycles, respectively, when the U.S. Department of Energy's three targeted new technologies were applied simultaneously.
\end{abstract}

\section{Introduction}

The United States has two important missions: to reduce oil consumption and to address global climate change. In the last two decades, heavy-duty vehicle design changes were driven by fuel economy (FE) and emissions regulations. Transportation accounts for about $77 \%$ of the domestic oil use and heavy-duty vehicles account for about $17 \%$ of transportation petroleum use [1]. According to government and industry statistics, class 8 trucks (gross vehicle weight rating is greater than $33,000 \mathrm{lb}$.) account for about two-thirds of all fuel use in the heavy-duty sector, and their lifetime fuel cost can be five times larger than the original purchase price of the vehicle [2]]. Separately, the request for high FE was driven by customer demand for reduced vehicle fuel consumption (FC). At the time of this writing, both regulations and customer demand are focused on increasing the efficiency of the whole vehicle, although the two thrusts may differ when overall operation economics and system efficiency are considered. The U.S. Environmental Protection Agency (EPA) and National Highway Traffic Safety Administration (NHTSA), in collaboration with the California Air Resources Board, plan to extend the greenhouse gas emission standards and FE standards for mediumand heavy-duty engines and vehicles through the application of advanced cost-effective technologies [ $\underline{3}$ ]. The effects of advanced technology on FC and emissions are presented in a final report to the U.S. Department of Energy (DOE) [4], which include factors like the coefficients of aerodynamic drag and rolling resistance, light-weight material, high-efficiency engines, and hybridization.

Heavy-duty vehicle manufacturers will need to comply with regulations and anticipate the rising costs of developing new technologies. A tool that can rapidly simulate multiple powertrain configurations without building costly physical prototypes is urgently needed. To meet this demand, the National Renewable Energy Laboratory (NREL) developed the Future Automotive System Technology Simulator (FASTSim) to evaluate the impact of technology improvements on efficiency, performance, cost, and battery life in conventional vehicles, hybrid electric vehicles, plug-in hybrid electric vehicles, and all-electric vehicles [5]. FASTSim provides researchers with inexpensive and effective modeling and simulation analyses of advanced vehicle technologies and performance.

\section{Metrics to Determine the Fuel Efficiency}

\section{Definition of Fuel Economy and Fuel Consumption}

$\mathrm{FE}$ and FC are metrics used to determine the fuel efficiency of vehicles. FC is defined by the amount of fuel consumed while traveling a certain distance and is usually expressed in gallons per 100 miles (or liters per $100 \mathrm{~km}$ ) [] $]$. FE is the distance traveled per 
unit of fuel used (expressed in miles per gallon [mpg]). The relationship between $\mathrm{FC}$ and $\mathrm{FE}$ is nonlinear. A $10 \%$ increase in $\mathrm{FE}$ corresponds to $9.1 \%$ decrease in FC, whereas a $100 \%$ increase in $\mathrm{FE}$ corresponds to a $50 \%$ decrease in FC. A given percentage improvement in FE saves less and less fuel as the FE increases [ 6 ]. For example, the amount of fuel saved for a light-duty vehicle when FE goes from $20 \mathrm{mpg}$ to $30 \mathrm{mpg}$ for 12,000 miles traveled is 200 gallons. The amount of fuel saved for a heavy duty vehicle when FE goes from 5 to $6 \mathrm{mpg}$ for the same 12,000 miles travels is 400 gallons. This example shows the importance of improving the FE of heavy-duty vehicles. A large amount of fuel can be saved by small improvements in FE.

\section{Heavy-Duty Diesel Truck Test Schedules}

In characterizing the FE from heavy-duty vehicles, it is essential that the vehicle is tested or simulated under typical in-use behavior. In this study, several cycles which cover a wide range of driving conditions were used. The Heavy Heavy-Duty Diesel Truck (HHDDT) schedule was originally created for the E55/59 study, which represented real-world truck activity in California $[\underline{7}, \underline{8}, \underline{9}, \underline{10}]$. The HHDDT schedule includes four modes: idle, creep, transient, and cruise modes. The creation of the HHDDT drive cycle has been discussed previously $[\underline{7}, \underline{8}, \underline{9}, \underline{10}]$. Each cycle has a unique idle time, average speed, stop times, acceleration, and deceleration. The creep mode has an average speed of less than two miles per hour ( $\mathrm{mph}$ ) over a distance of 0.12 mile [9]. The transient mode has a higher average speed of 15.34 miles per hour over a distance of 2.8 miles. The transient mode is the typical stop-and-go behavior for a heavy-duty truck in an urban area [9]. The cruise mode represents freeway travel. HHDDT represents both the high-speed cruise that characterizes similar highway behavior in congested urban areas and south-north travel along Highway 99 and Interstate 55 [9]. The WVU City cycle represents typical city driving for heavy-duty vehicles. The basic parameters of the WVU City cycle include a 1,300-second duration, an 8.39-mph average speed, and a 35.6-mph maximum trip speed [10]. The Combined International Local and Commuter Cycle (CILCC) is a composite cycle for heavy-duty vehicles developed by NREL, Eaton, and International Truck and Engine. The characteristics of CILCC comprise a 3,192-second duration and a 13.89-mph average speed over a 12.32-mile distance trip [11]. Chassis dynamometer testing was performed over the HHDDT, WVU City, and CILCC cycles on one conventional and one hybrid regional delivery heavy-duty truck at NREL's Renewable Fuels and Lubricants (ReFUEL) Laboratory. Time-speed traces of these cycles are shown in Figures $1, \underline{2}, \underline{3}$.

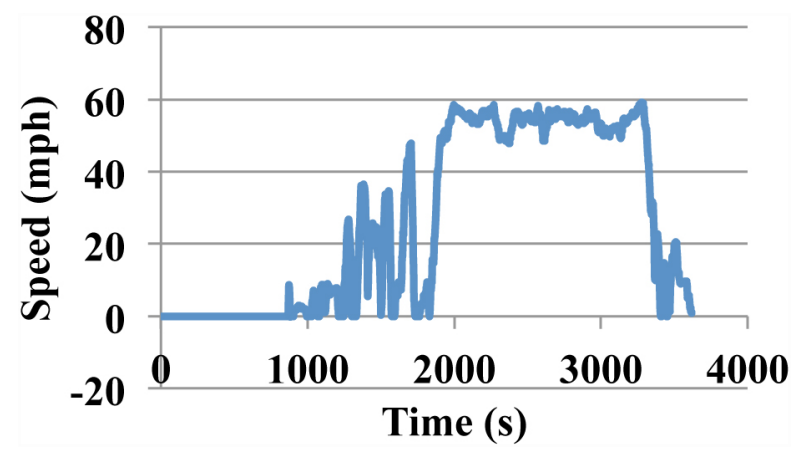

Figure.1. HHDDT trace.

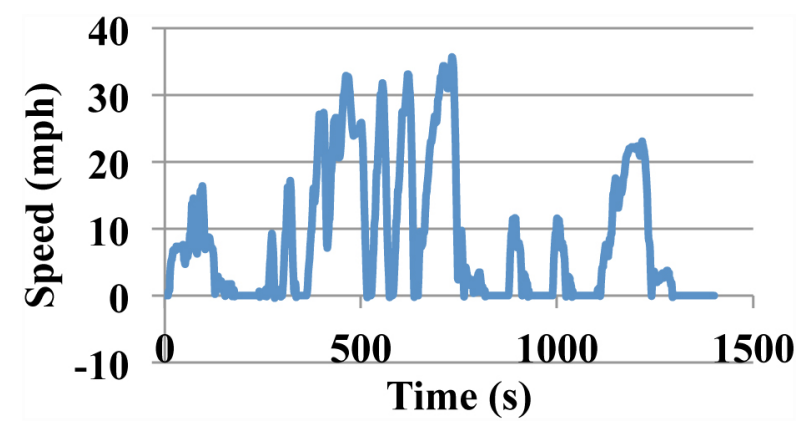

Figure 2. WVU City Trace.

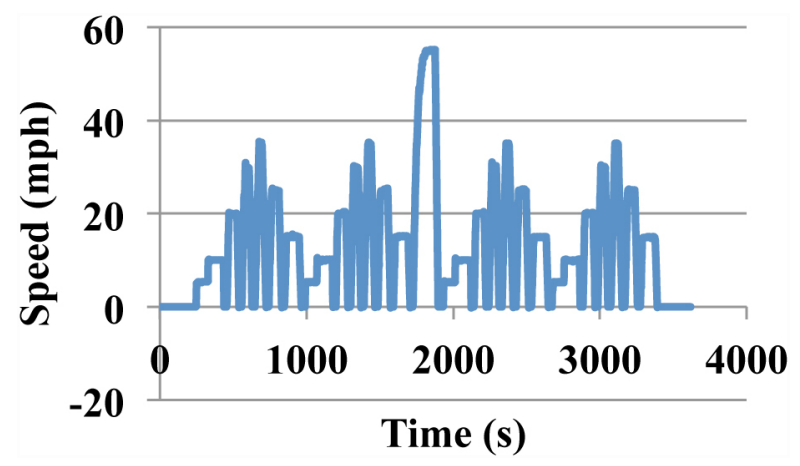

Figure 3. CILCC trace.

\section{The FASTSim Vehicle Model}

The heavy-duty vehicle used in this research was a conventional regional delivery truck with a 284-HP (212-kW) Cummins engine. The vehicle was tested on the HHDDT, WVU City, and CILCC cycles on the chassis dynamometer at NREL's ReFUEL Laboratory to provide continuous fuel rate data. Figure 4 shows the regional delivery truck that was used in this study. Detailed test information about the vehicle is presented in Table 1.

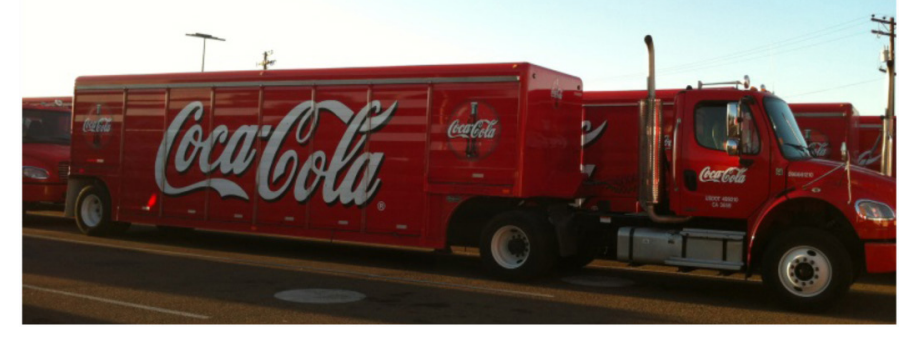

Figure 4. Regional delivery truck (Photo was taken by ReFuel).

Table 1. Specifications of the Regional Delivery Truck

\begin{tabular}{|l|l|}
\hline Vehicle Type & Class 8 Truck \\
\hline Vehicle Tested Weight (lb.) & 33,237 \\
\hline Tire Size & $305 / 70 \mathrm{R} 22.5$ \\
\hline Coefficient of Rolling Resistance & 0.0085 \\
\hline Coefficient of Aerodynamic Drag & 0.7963 \\
\hline Frontal Area (m ${ }^{2}$ ) & 9.5 \\
\hline Engine Power (HP) & 284 \\
\hline Test Cycle & HHDDT, WVU City, and CILCC \\
\hline
\end{tabular}


The regional delivery truck was modeled and validated by using FASTSim running on the HHDDT, WVU City, and CILCC cycles. The truck model was validated by comparing the fuel rates from the chassis dynamometer test and the FASTSim simulation. The achieved relative errors were all within $2 \%$. The results showed that the truck model was sufficiently validated and could be used as the basis for future parametric studies. The validation results are summarized in Table 2. In Table 2, the relative errors were used to evaluate performance between the test and FASTSim simulated results. Equation 1 provides the mathematical definitions for this criterion:

$$
R E=\frac{(\hat{y}-y) * 100 \%}{y}
$$

where $y$ and $\widehat{y}$ are the tests and the FASTSim simulated FC, and $R E$ is relative error.

Table 2. Summaries of Tested Validation Results for Coke-Cola Truck.

\begin{tabular}{|l|l|l|l|}
\hline $\begin{array}{l}\text { Fuel Consumption } \\
(\mathrm{L} / 100 \mathrm{~km})\end{array}$ & Tested & $\begin{array}{l}\text { FASTSim } \\
\text { Simulated }\end{array}$ & $\begin{array}{l}\text { RE } \\
(\%)\end{array}$ \\
\hline HHDDT & 38.70 & 38.35 & -0.90 \\
\hline WVU City & 50.72 & 50.84 & 0.24 \\
\hline CILCC & 38.42 & 38.93 & 1.32 \\
\hline
\end{tabular}

\section{Parametric Study on Fuel Consumption and Fuel Economy}

In this section, we estimate the $\mathrm{FC}$ and $\mathrm{FE}$ of the regional delivery truck over various cycles as a function of key parameters from a parametric analysis.

\section{Impact of Single Technologies on Fuel Consumption}

\section{Aerodynamic Drag}

Aerodynamic drag is a force opposing the motion of the vehicle caused by the resistance of ambient air. Quantitatively, the aerodynamic drag is proportional to the product of the coefficient of aerodynamic drag, the frontal area, and the square of vehicle velocity, as shown in Equation 2.

$$
F_{d r a g}=0.5 C_{d} \rho A V^{2}
$$

where $V$ is vehicle speed $(\mathrm{m} / \mathrm{s}), C_{d}$ is coefficient of aerodynamic drag, $\rho$ is air density $\left(\mathrm{kg} / \mathrm{m}^{3}\right)$, and $A$ is frontal area. The coefficient of aerodynamic drag for current heavy-duty vehicles with smooth-sided van trailers is about $0.6-0.85$, which is higher than the value found for light-duty vehicles, which is normally about 0.3 to 0.4 [6]. The higher values for heavy-duty vehicles are due to the fact that they are equipped with large boxes (with larger frontal areas than light-duty vehicles) to carry freight. The metric for evaluating aerodynamic losses is the coefficient of aerodynamic drag. Reducing the frontal area usually sacrifices the interior size and thus has limited value in reducing aerodynamic drag. Driving slower can also reduce the drag force. However, changing the actual road speed is not realistic, so reducing the drag coefficient is the main way to reduce aerodynamic drag. The regional delivery truck was simulated by FASTSim for various driving cycles at different weights and coefficients of aerodynamic drag and rolling resistance. Figure 5 depicts the impact of the coefficient of aerodynamic drag on FE at a constant test weight and rolling resistance. Three different driving schedules, HHDDT, WVU City, and CILCC, were chosen to represent various driving conditions. It can be seen that the FCs are approximately linear functions of the coefficient of aerodynamic drag over the HHDDT, WVU City, and CILCC cycles. There is some benefit for aerodynamic drag reduction from medium-speed cycles (WVU City and CILCC), and a large benefit can be achieved during high-speed cycles (HHDDT). If the coefficient of aerodynamic drag is reduced from the proposed EPA/NHTSA baseline coefficient of 0.69 to 0.48 (30\% reduction from DOE baseline number) [12], a 13\% FC savings is achieved for the regional delivery truck during HHDDT mode.

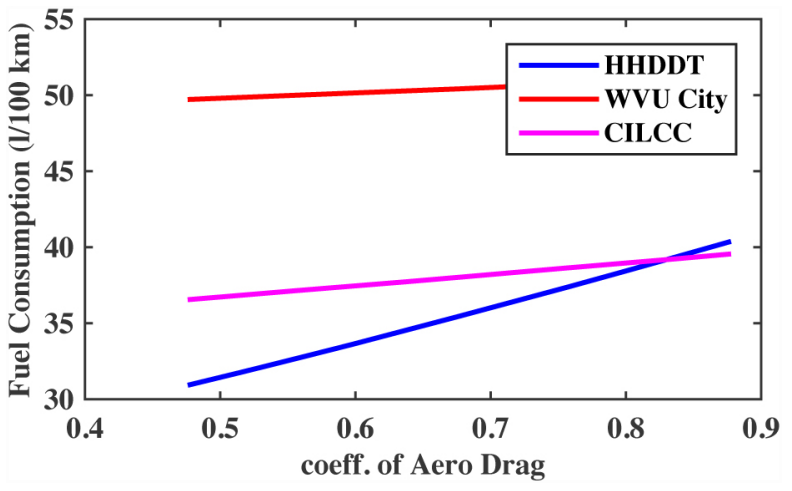

Figure 5. The impact of coefficient of aerodynamic drag on FC for a regional delivery truck over various driving cycles (truck weight $=33,237 \mathrm{lbs}$., coefficient of rolling resistance $\mu=0.0085$, and frontal area $9.5 \mathrm{~m}^{2}$ ).

\section{Rolling Resistance}

Tire rolling resistance accounts for around $30 \%$ of the vehicle resistance to forward motion [12]. Figure 6 shows the impacts of coefficient of rolling resistance on FC for the truck over different cycles at a constant test weight and aerodynamic drag. It can be seen that the FC is linearly proportional to the coefficient of rolling resistance over the different duty cycles. If the coefficient of rolling resistance is reduced from the EPA/NHTSA baseline of 0.0082 to 0.0053 (35\% reduction, which is the DOE target number) [12], a $9 \%$ FC savings would be achieved for the regional delivery truck over the HHDDT mode.

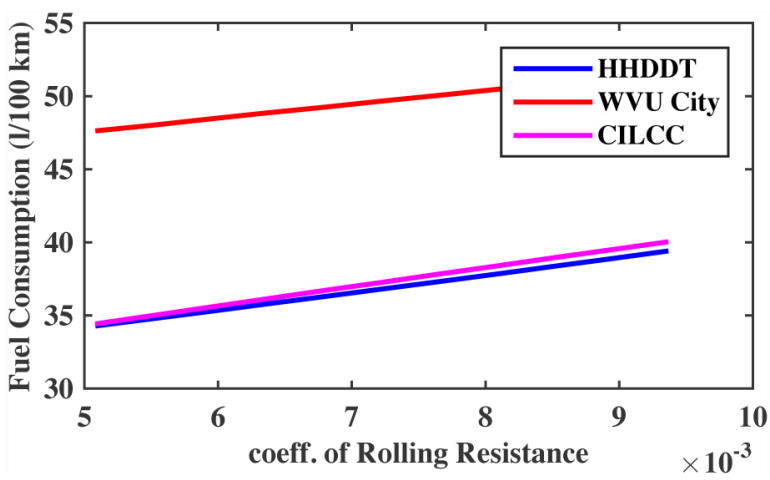

Figure 6. The impact of coefficient of aerodynamic drag on fuel consumption for a regional delivery truck over various driving cycles (truck weight $=33,237$ lbs., coefficient of rolling resistance $\mu=0.0085$, and frontal area $=9.5 \mathrm{~m}^{2}$ ). 


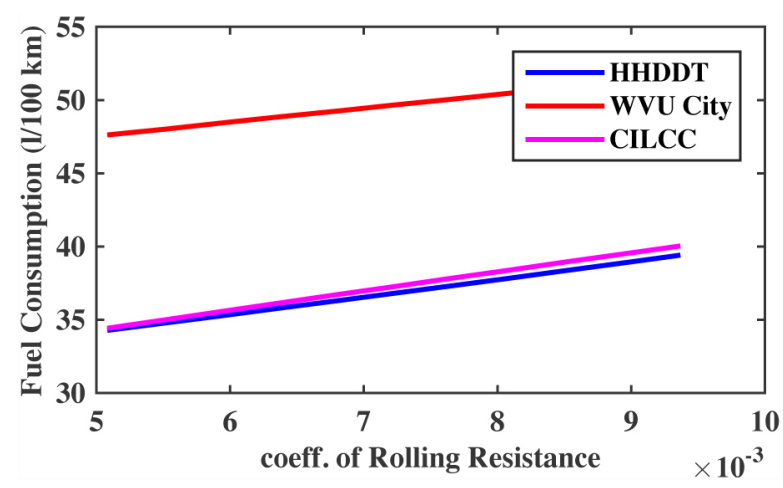

Figure 6. (cont.) The impact of coefficient of aerodynamic drag on fuel consumption for a regional delivery truck over various driving cycles (truck weight $=33,237 \mathrm{lbs}$., coefficient of rolling resistance $\mu=0.0085$, and frontal area $=9.5 \mathrm{~m}^{2}$ ).

\section{Vehicle Weight}

The vehicle weight affects the engine power required to propel the vehicle through acceleration, rolling resistance, and hill climbing. A full loaded tractor-trailer vehicle can weigh up to $80,000 \mathrm{lbs}$.

Reducing the vehicle's weight could increase in freight delivered on a ton-mile basis and improve the freight transportation efficiency.

Figure 7 depicts the influence of weight on FC over various cycles. There is some benefit in weight reduction on the HHDDT and CILCC cycles, and a large benefit can be achieved during the high transient speed cycle, WVU City. This simulation shows an $8 \%$ FC reduction over the HHDDT cycle when the vehicle weight is decreased from $36,000 \mathrm{lbs}$. to $28,800 \mathrm{lbs}$. ( $20 \%$ weight reduction, which is the long-term goal of reducing combined vehicle weight [12]). In other words, it is expected to see a $1 \%$ fuel saving for every $1,000 \mathrm{lbs}$. of vehicle weight reduced over the HHDDT cycle. A $12 \%$ FC reduction was achieved when decreasing the vehicle weight from $36,000 \mathrm{lbs}$. to $28,800 \mathrm{lbs}$. for the WVU City cycle. There is more impact in the real world because of the grade.

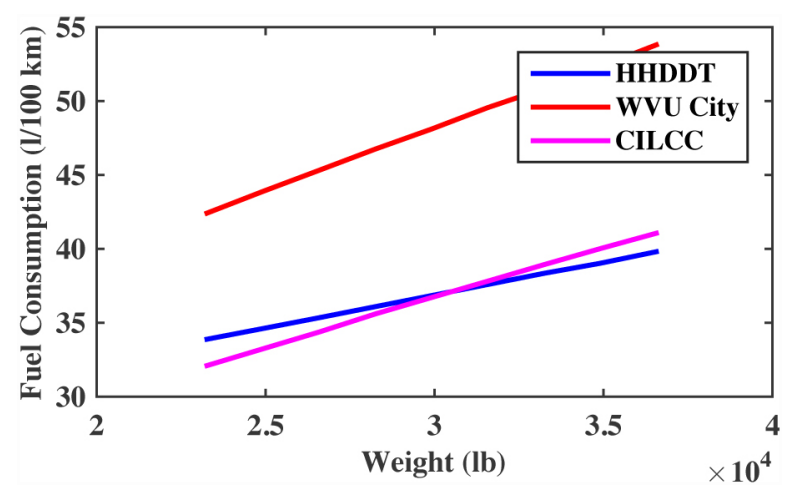

Figure 7. The impact of weight on fuel consumption for a regional delivery truck over various driving cycles (coefficient of aerodynamic drag $\mathrm{C}_{\mathrm{d}}=$ 0.7963 , coefficient of rolling resistance $\mu=0.0085$, and frontal area $9.5 \mathrm{~m}^{2}$ ).

\section{The Elasticity of Fuel Consumption}

There is another way to view the impacts of parametric variation on FC. Table 3 shows the variations of FC over different cycles while keeping some parameters constant and varying others by subtracting or adding $5 \%$ to the base numbers. The base numbers used were as follows:

Weight: 33,237 lbs.

Coefficient of aerodynamic drag: 0.7963

Coefficient of rolling resistance: 0.0085

Elasticity describes the relation between the proportional change in the dependent variable (FC) in response to a proportional change in the independent variable (weight, rolling resistance, or aerodynamic drag) $[13,14]$. For example, the elasticity of FC with respect to weight describes the percent change in $\mathrm{FC}$ in response to a given percentage change of weight. The elasticity of FC with respect to the variables can be expressed by equation 3 [13].

$$
\varepsilon_{x}=\frac{d F C / F C}{d x / x}
$$

where $\varepsilon_{x}$ represents the elasticity of FC with respect to $x$, and $x$ represents vehicle weight $(W)$, coefficient of rolling resistance $(\mu)$, or coefficient of aerodynamic drag $\left(C_{d}\right)$. Table 4 shows the elasticity of $\mathrm{FC}$ with respect to weight, rolling resistance, and aerodynamic drag. From Table 4, it can be seen that the FC varies with truck weight with an elasticity of $0.3-0.6$ over the HHDDT, WVU City and CILCC cycles, which indicates that a $10 \%$ reduction in weight can produce a $3 \%-6 \% \%$ decrease in FC. Similarly, a 10\% reduction in rolling resistance can produce a $2 \%-3 \%$ decrease in FC. The elasticity of FC with aerodynamic drag is highly dependent on the driving cycle. The elasticity of FC was 0.51 over the high-speed HHDDT cycle while it was only 0.05 over the WVU City cycle. Overall, weight has the largest elasticity of FC of all the parameters.

Table 3. Fuel consumption over different cycles by subtracting $5 \%$ from the base or adding $5 \%$ to the base numbers (weight $=33,273 \mathrm{lbs}$., coefficient of aerodynamic drag $=0.7963$, coefficient of rolling resistance $=0.0085$, and frontal area $\mathrm{A}=9.5 \mathrm{~m}^{2}$ ).

\begin{tabular}{|l|l|l|l|l|l|l|}
\hline \multirow{4}{*}{ Cycle } & $\begin{array}{l}\text { Weight } \\
(\mathrm{lb} .)\end{array}$ & $\begin{array}{l}\text { FC } \\
(\mathrm{L} / 100 \\
\mathrm{km})\end{array}$ & $\begin{array}{l}\text { Coefficient } \\
\text { of Rolling } \\
\text { Resistance }\end{array}$ & $\begin{array}{l}\text { FC } \\
(\mathrm{L} / 100 \\
\mathrm{km})\end{array}$ & $\begin{array}{l}\text { Coefficient } \\
\text { of Aero } \\
\text { Drag }\end{array}$ & $\begin{array}{l}\text { FC } \\
(\mathrm{L} / 100 \\
\mathrm{km})\end{array}$ \\
\hline \multirow{4}{*}{ HHDDT } & 31,609 & 37.6044 & 0.00808 & 37.8262 & 0.7565 & 37.3675 \\
\cline { 2 - 7 } & 33,273 & 38.3464 & 0.0085 & 38.3464 & 0.7963 & 38.3464 \\
\cline { 2 - 7 } & 34,937 & 39.0385 & 0.00893 & 38.8682 & 0.8361 & 39.3367 \\
\hline \multirow{4}{*}{$\begin{array}{l}\text { WVU } \\
\text { City }\end{array}$} & 31,609 & 49.5828 & 0.00808 & 50.4592 & 0.7565 & 50.7072 \\
\cline { 2 - 7 } & 33,273 & 50.8451 & 0.0085 & 50.8451 & 0.7963 & 50.8451 \\
\hline \multirow{4}{*}{ CILCC } & 34,937 & 52.3768 & 0.00893 & 51.2637 & 0.8361 & 50.9826 \\
\cline { 2 - 7 } & 33,273 & 38.9328 & 0.0085 & 38.9328 & 0.7963 & 38.9328 \\
\cline { 2 - 7 } & 34,937 & 40.0342 & 0.00893 & 39.4795 & 0.8361 & 39.2286 \\
\hline
\end{tabular}


Table 4. Elasticity of FC with respect to weight, rolling resistance, and aerodynamic drag.

\begin{tabular}{|c|c|c|c|c|c|c|}
\hline Cycle & $\begin{array}{l}\text { Weight } \\
\text { (lb.) }\end{array}$ & $\varepsilon \mathrm{W}$ & $\begin{array}{l}\text { Coefficient } \\
\text { of Rolling } \\
\text { Resistance }\end{array}$ & $\varepsilon \mathrm{RR}$ & $\begin{array}{l}\text { Coefficient } \\
\text { of Aero } \\
\text { Drag }\end{array}$ & $\varepsilon \mathrm{C}_{\mathrm{d}}$ \\
\hline \multirow{3}{*}{ HHDDT } & 31,609 & \multirow{3}{*}{0.3739} & 0.00808 & \multirow{3}{*}{0.2717} & 0.7565 & \multirow{3}{*}{0.5137} \\
\hline & 33,273 & & 0.0085 & & 0.7963 & \\
\hline & 34,937 & & 0.00893 & & 0.8361 & \\
\hline \multirow{3}{*}{$\begin{array}{l}\text { WVU } \\
\text { City }\end{array}$} & 31,609 & \multirow{3}{*}{0.5494} & 0.00808 & \multirow{3}{*}{0.1582} & 0.7565 & \multirow{3}{*}{0.0542} \\
\hline & 33,273 & & 0.0085 & & 0.7963 & \\
\hline & 34,937 & & 0.00893 & & 0.8361 & \\
\hline \multirow{3}{*}{ CILCC } & 31,609 & \multirow{3}{*}{0.5599} & 0.00808 & \multirow{3}{*}{0.2834} & 0.7565 & \multirow{3}{*}{0.1520} \\
\hline & 33,273 & & 0.0085 & & 0.7963 & \\
\hline & 34,937 & & 0.00893 & & 0.8361 & \\
\hline
\end{tabular}

\section{Impact of Multiple Technologies on Fuel Economy}

\section{Two Technologies}

As seen above, the FC and FE significantly differ when the different parameters are chosen. This section will provide a method to estimate the FE of the regional delivery truck over various cycles as a function of two parameters (such as coefficients of aerodynamic drag and rolling resistance, vehicle weight and coefficient of rolling resistance, and vehicle weight and coefficient of aerodynamic drag). Figures 8 , $\underline{9}, \underline{10}$ show a parametric sweep conducted on the truck model over HHDDT, WVU City, and CILCC. The FC contours are a function of the coefficients of aerodynamic drag and rolling resistance at a constant truck weight (37,273 lbs.).

A trend can be seen from these grouped FE contour lines. In the high FE region, the lines are closer and have deep gradients, while the gradient was lower at low FE, which was believed to lie with the definition of FE [15], i.e., FE is the amount of fuel consumed over a given distance. The rate of change of FE can be obtained with a derivative, as shown by Equation 4 .

$$
\frac{d(D / V)}{d V}=-\frac{D}{V^{2}}
$$

where $D$ is a constant distance traveled, $V$ is volume of FC over this distance, and $D / V$ is the fuel economy. Figures $8, \underline{9}, \underline{10}$ also demonstrate how FE is influenced relatively by the parameters.

In Figure 8, in the HHDDT mode, for example, when the coefficient of aerodynamic drag is 0.77 and the coefficient of rolling resistance is 0.0069 , it could be concluded that decreasing the coefficient of aerodynamic drag by 0.08 ( $10 \%$ aerodynamic drag reduction) has the same effect as reducing the coefficient of rolling resistance by 0.0005 ( $7 \%$ rolling resistance reduction). This suggests that, depending on the circumstances, it may be more cost effective to reduce one parameter (such as coefficient of aerodynamic drag) to increase fuel economy, or it may be more beneficial to reduce another (such as the coefficient of rolling resistance). Another function of these contour figures is to provide a convenient way to estimate FE by interpolating within the parameter values and extrapolating outside of them.

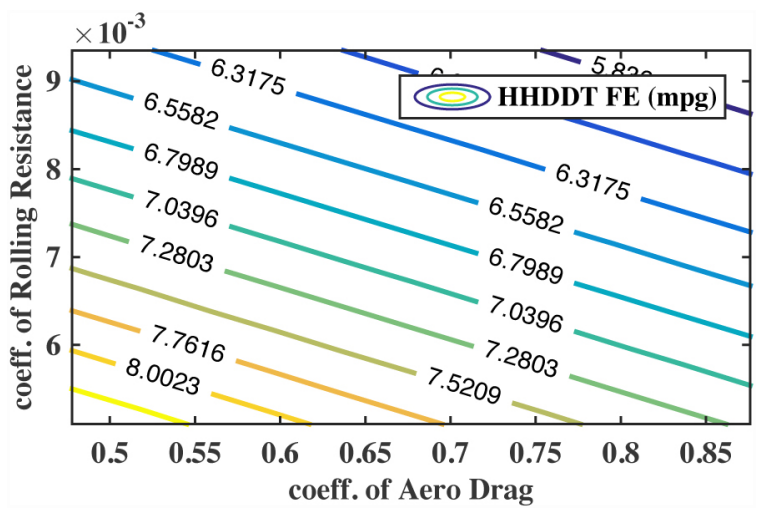

Figure 8. FE contour map for a regional delivery truck on various coefficients of rolling resistance and aerodynamic drag over HHDDT (truck weight $=$ 37,273 lbs.)

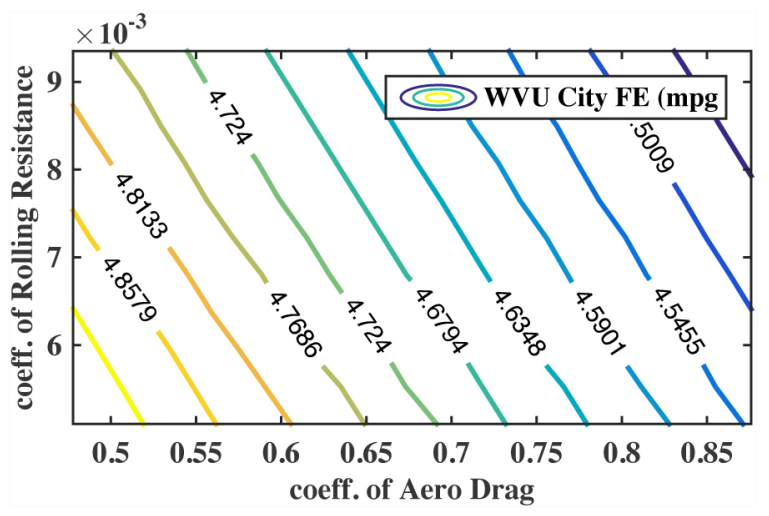

Figure 9. FE contour map for a regional delivery truck on various coefficients of rolling resistance and aerodynamic drag over WVU City (truck weight = 37,273 lbs.)

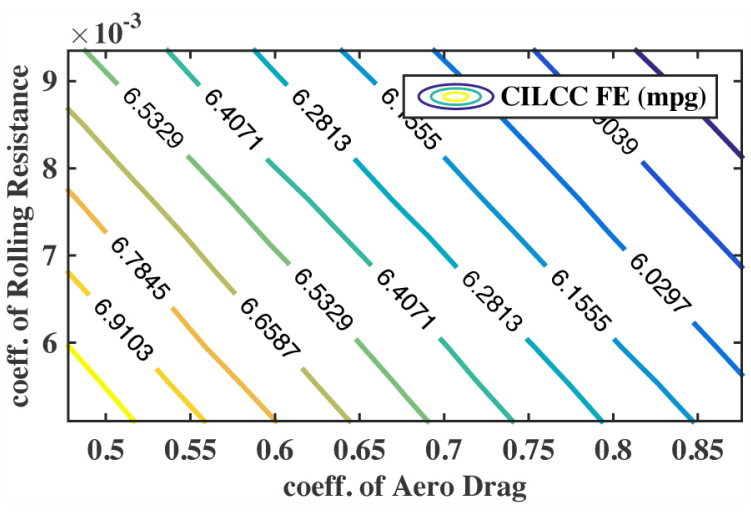

Figure 10. FE contour map for a regional delivery truck on various coefficients of rolling resistance and aerodynamic drag over CILCC (truck weight $=37,273 \mathrm{lbs}$.).

Other cases analyzing how FE can be influenced by multiple parameters are shown in Figures $11, \underline{12}, \underline{13}$, which demonstrate the FE contour figures on various coefficients of rolling resistance and truck weight at a constant coefficient of aerodynamic drag $\left(C_{d}=\right.$ 0.7963) over HHDDT, WVU City, and CILCC. 
Figures $11, \underline{12}, \underline{13}$ illustrate a similar trend between FE and the individual variables (vehicle weight and coefficients of rolling resistance) used to construct the contour maps. The contour lines are closer and the gradients are larger at high FE. In contrast, the contour lines spread, and the gradients are smaller at low FE. As stated, the contour maps can be used to find the relative change in FE by parameter. For instance, in examining the FE in Figure 11 for the HHDDT mode, it was observed that reducing the truck weight from $32,000 \mathrm{lbs}$. to $27,000 \mathrm{lbs}$. (16\% weight reduction) had the same impact on reducing the coefficient of rolling resistance from 0.0072 to 0.0064 (11\% reduction). Likewise, Figures $11,12,13$ can be used to estimate FE by interpolating within the parameter values and extrapolating outside of them.

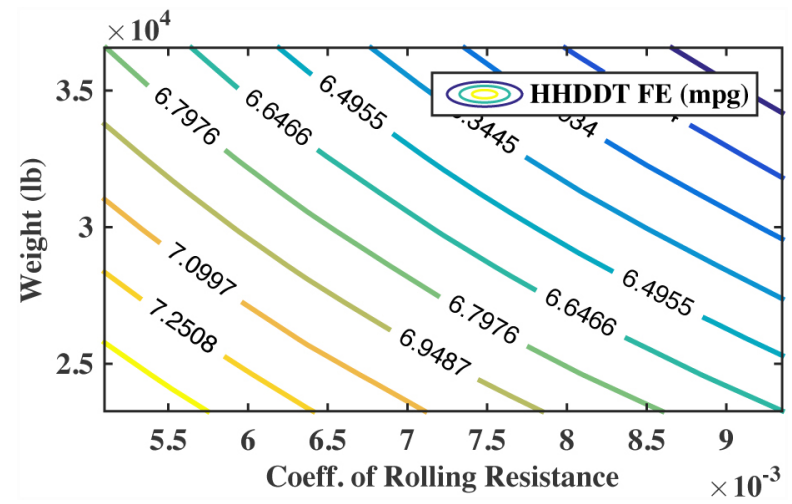

Figure 11. FE contour map for a regional delivery truck on various coefficients of rolling resistance and truck weights over HHDDT mode (coefficient of aerodynamic drag $C_{d}=0.7963$ and frontal area $\mathrm{A}=9.5 \mathrm{~m}^{2}$ ).

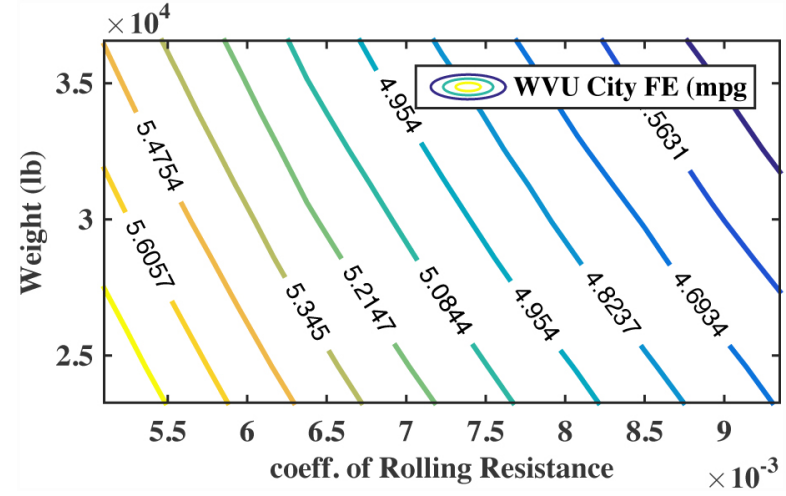

Figure 12. FE contour map for a regional delivery truck on various coefficients of rolling resistance and truck weight over WVU City (coefficient of aerodynamic drag $C_{d}=0.7963$ and frontal area $\mathrm{A}=9.5 \mathrm{~m}^{2}$ ).

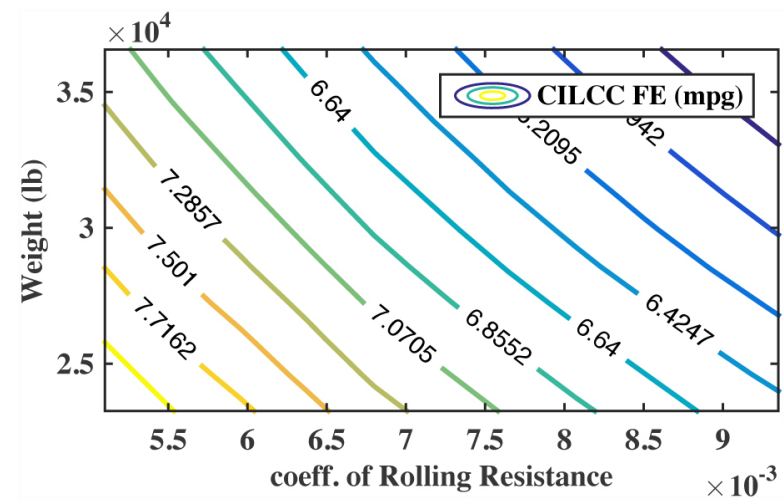

Figure 13. FE contour map for a regional delivery truck on various coefficients of rolling resistance and truck weight over CILCC (coefficient of aerodynamic drag $C_{d}=0.7963$ and frontal area $\mathrm{A}=9.5 \mathrm{~m}^{2}$ ).
In a similar way, Figures $14, \underline{15}, \underline{16}$ illustrate a trend between FE and the individual variables (vehicle weight and coefficient of aerodynamic drag) at a constant coefficient of rolling resistance $(\mu=$ 0.0085 ) over HHDDT, WVU City and CILCC. It can be seen that reducing the truck weight from $28,000 \mathrm{lbs}$. to $26,000 \mathrm{lbs}$. (7\% weight reduction) had the same impact on reducing the coefficient of rolling resistance from 0.0075 to 0.0067 (11\% reduction). Equally, Figures $\underline{14}, \underline{15}, \underline{16}$ can be used to estimate FE by interpolating within the parameter values and extrapolating outside of them.

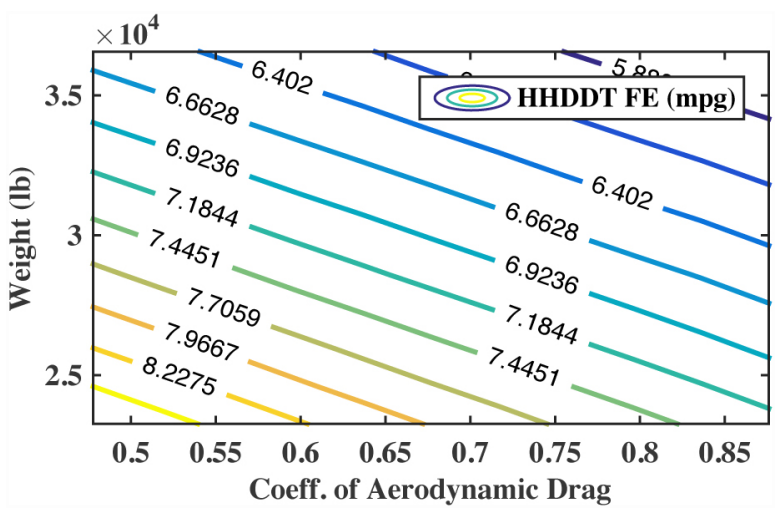

Figure 14. FE contour map for a regional delivery truck on various coefficients of aerodynamic drag and truck weight over HHDDT mode (coefficient of rolling resistance $\mu=0.0085$ ).

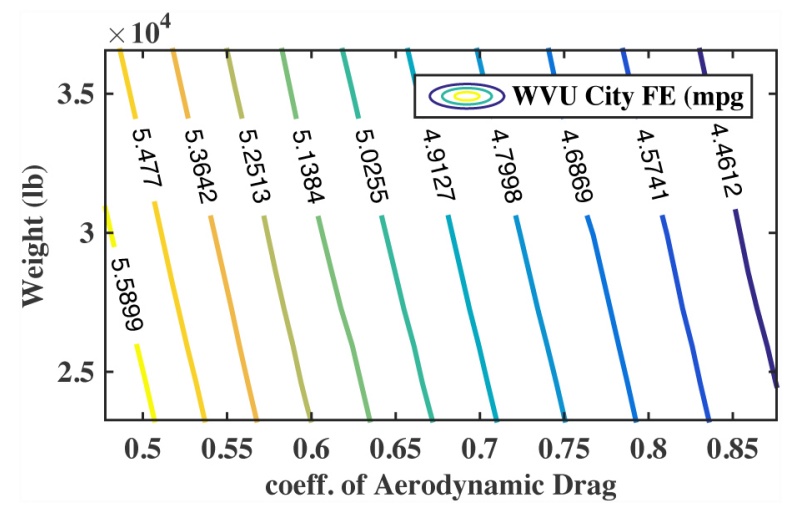

Figure 15. FE contour map for a regional delivery truck on various coefficients of aerodynamic drag and truck weight over WVU City mode (coefficient of rolling resistance $\mu=0.0085$ )

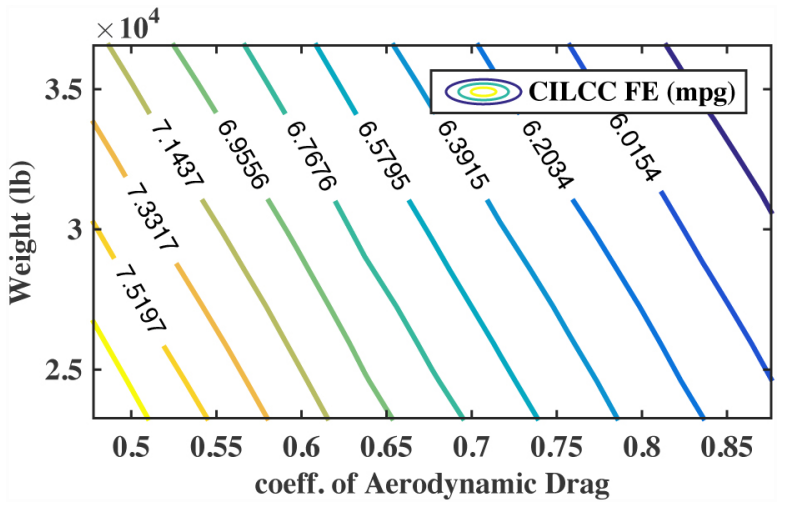

Figure 16. FE contour map for a regional delivery truck on various coefficients of aerodynamic drag and truck weight over CILCC mode (coefficient of rolling resistance $\mu=0.0085$ ). 


\section{Three Technologies}

The FCs of the regional delivery truck over various cycles as a function of weight and coefficients of aerodynamic drag and rolling resistance are shown in Figures 17, $\underline{18}, \underline{19}$. As stated, the FCs for baseline case (weight $=33,237 \mathrm{lbs} ., \mu=0.0085$ and $C_{d}=0.7963$ ) are $38.70 \mathrm{~L} / 100 \mathrm{~km}, 50.72 \mathrm{~L} / 100 \mathrm{~km}$ and $38.42 \mathrm{~L} / 100 \mathrm{~km}$ over HHDDT, WVU City, and CILCC. With DOE's new technology goal assumptions [12] (weight $=28,800$ lbs., $\mu=0.0053$, and $C_{d}=0.48$ ), a $\mathrm{FC}$ as low as $26.78 \mathrm{~L} / 100 \mathrm{~km}, 43.14 \mathrm{~L} / 100 \mathrm{~km}$, and $29.84 \mathrm{~L} / 100 \mathrm{~km}$ can be achieved over HHDDT, WVU City, and CILCC, respectively.

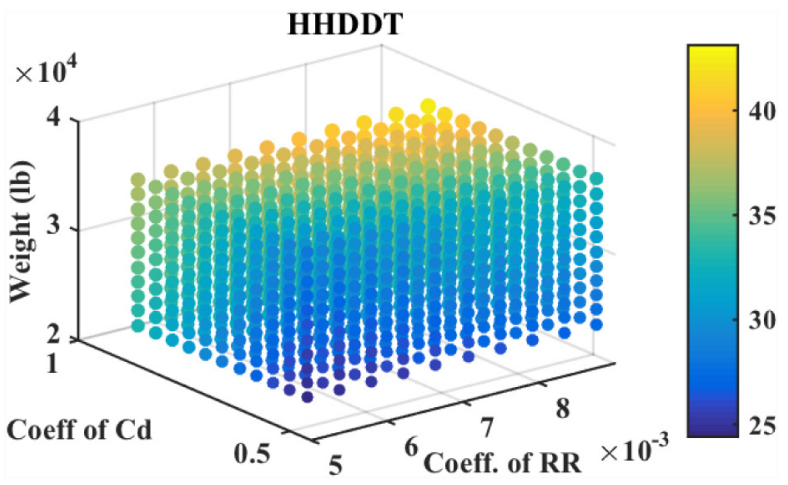

Figure 17. FC for a regional delivery truck for various truck weights and coefficients of aerodynamic drag and rolling resistance over HHDDT.

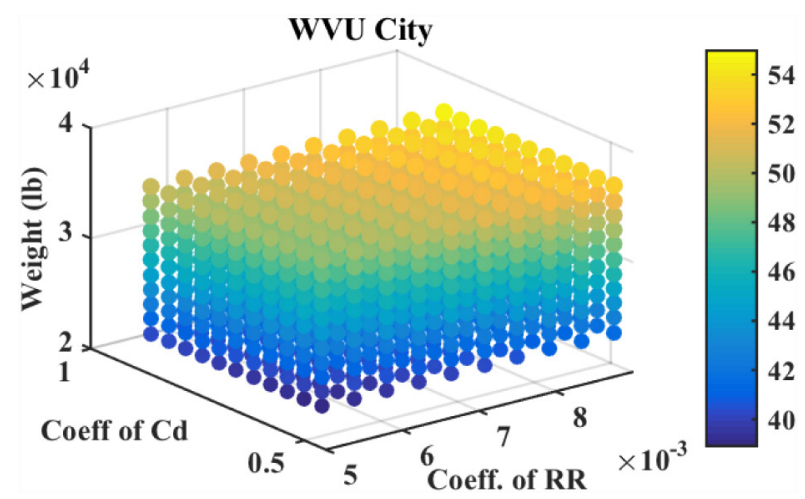

Figure 18. FC for a regional delivery truck for various truck weights and coefficients of aerodynamic drag and rolling resistance over WVU City.

CILCC

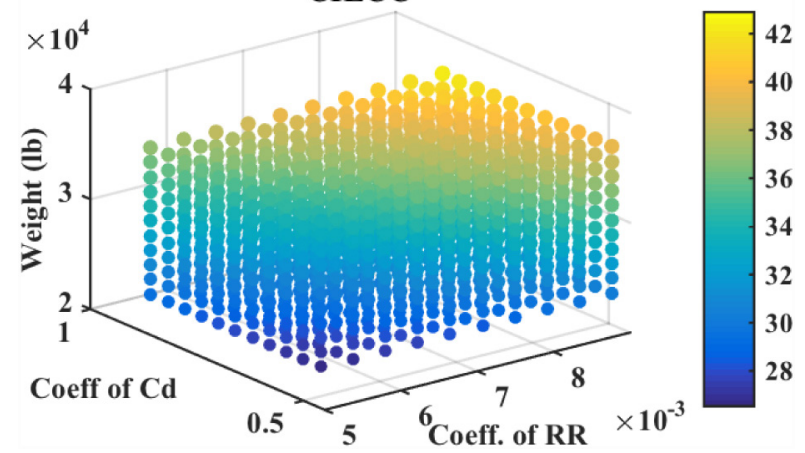

Figure 19. FC for a regional delivery truck for various truck weights and coefficients of aerodynamic drag and rolling resistance over CILCC.

\section{Summary}

The impacts of various factors on FC and FE were investigated by simulating the regional delivery truck using FASTSim over the HHDDT, WVU City, and CILCC drive cycles. The study of the effect of single technologies on $\mathrm{FC}$ reveal that a $30 \%$ aerodynamic drag reduction, $35 \%$ rolling resistance reduction, and $20 \%$ weight reduction would achieve at most $13 \%, 9 \%$ and $12 \%$ FC savings, respectively. The study of the effect of two technologies on FE implied that it might be more cost effective to reduce one parameter to increase FE or it might be more beneficial to reduce another, depending on the cost circumstances. The FC could be reduced from $38.70 \mathrm{~L} / 100 \mathrm{~km}, 50.72 \mathrm{~L} / 100 \mathrm{~km}$, and $38.42 \mathrm{~L} / 100 \mathrm{~km}$ baseline truck to $26.78 \mathrm{~L} / 100 \mathrm{~km}, 43.14 \mathrm{~L} / 100 \mathrm{~km}$, and $29.84 \mathrm{~L} / 100 \mathrm{~km}$ over the HHDDT, WVU City and CILCC drive cycles, respectively, when applied to DOE's three targeted new technologies simultaneously.

A cost-effectiveness analysis will be conducted for future work.

\section{References}

1. U.S. Energy Information Administration, "EIA Annual Energy Outlook 2010 with Projections to 2035," DOE/EIA-0383(2010). http://www.eia.gov/oiaf/aeo/pdf/0383(2010).pdf, accessed April $6,2015$.

2. U.S. Department of Energy, "Research and Development Opportunities for Heavy Trucks," June 2009. http://www1.eere. energy.gov/vehiclesandfuels/pdfs/truck_efficiency_paper_v2.pdf

3. U. S. Environmental Protection Agency, "Regulations \& Standards: Heavy-duty - Extending the Greenhouse Gas Emissions Standards and Fuel Efficiency Standards for Mediumand Heavy-Duty Engines and Vehicles," http://www.epa.gov/ otaq/climate/regs-heavy-duty.htm, accessed March 2015.

4. TA Engineering, Inc., "DOE SuperTruck Program Benefits Analysis," http://www.transportation.anl.gov/pdfs/TA/903.PDF, accessed March 2015.

5. National Renewable Energy Laboratory, "Future Automotive System Technology Simulator," http://www.nrel.gov/ transportation/fastsim.html, accessed April 6, 2015.

6. Committee to Assess Fuel Economy Technologies for Medium-and Heavy-Duty Vehicles, National Research Council, and Transportation Research Board, "Technologies and Approaches to Reducing the Fuel Consumption of Medium- and Heavy-Duty Vehicles," Washington, D.C., The National Academies Press, 2010. https://www.nap.edu/login. php?record id=12845\&page $=$ http $\% 3 \mathrm{~A} \% 2 \mathrm{~F} \% 2 \mathrm{Fwww}$.nap. edu $\% 2$ Fdownload.php $\% 3$ Frecord_id $\% 3$ D 12845

7. Clark, N.N., Gautam, M., Wayne, W.S., Thompson, G.J., et al., "California Heavy Heavy-Duty Diesel Truck Emissions Characterization for Project E-55/E-59 Phase 1.5," CRC Project E-55/59 Report, August 2004. http://crcao.org/reports/ recentstudies2004/E55-1.5\%20FINAL\%20REPORT\%20 Aug\%2020.pdf, accessed April 6, 2015. 
8. Code of Federal Regulations, Title 40, "Protection of the Environment, CFR Appendix I to Part 86 - Urban Driving Dynamometer Schedule," Washington, D.C., U.S. Government Printing Office, 2005.

9. Clark, N., Tehranian, A., Jarrett, R., and Nine, R., "Translation of Distance-Specific Emissions Rates between Different Heavy Duty Vehicle Chassis Test Schedules," SAE Technical Paper 2002-01-1754, 2002, doi:10.4271/2002-01-1754.

10. Clark, N., Gautam, M., Wayne, W., Nine, R. et al., "Creation and Evaluation of a Medium Heavy-Duty Truck Test Cycle," SAE Technical Paper 2003-01-3284, 2003, doi:10.4271/200301-3284.

11. Lammert, C., "Twelve-Month Evaluation of UPS Hybrid Electric Delivery Vans," Technical Report, Golden, CO, National Renewable Energy Laboratory, NREL/TP-540-44134 December 2009.

12. U.S. Department of Energy Office Energy and Efficiency and Renewable Energy, "Roadmap and Technical White Papers, 21st Century Truck Partnership,” February 2013, http://energy.gov/ sites/prod/files/2014/02/f8/21ctp_roadmap_white_papers_2013. pdf, accessed April 6, 2015.

13. Landau, L.D., and Lifshitz, E.M., "Theory of Elasticity, Third Edition," Volume 7, Course of Theoretical Physics, ButterworthHeinemann, Oxford, UK, 1986, ISBN: 978-0-08-057069-3.

14. O'Keefe, M.P., and Vertin, K., "An Analysis of Hybrid Electric Propulsion Systems for Transit Buses," Golden, CO, National Renewable Energy Laboratory, October 2002, http://www.nrel. gov/docx/gen/fy03/32858.pdf, accessed April 6, 2015.

15. Wohlecker, R., Johannaber, M., and Espig, M., "Determination of Weight Elasticity of Fuel Economy for ICE, Hybrid and Fuel Cell Vehicles," SAE Technical Paper 2007-01-0343, 2007, doi: 10.4271/2007-01-0343.

\section{Contact Information}

Lijuan Wang

Lijuan.wang@nrel.gov

\section{Acknowledgments}

The authors would like to acknowledge Dr. Nigel Clark for giving direction to this study. Without his guidance, the demonstration of this method would not have been possible.

This work was supported by the U.S. Department of Energy under Contract No. DE-AC36-08GO28308 with the National Renewable Energy Laboratory. Funding was provided by U.S. DOE Office of Energy Efficiency and Renewable Energy Vehicle Technologies Office.

The U.S. Government retains and the publisher, by accepting the article for publication, acknowledges that the U.S. Government retains a nonexclusive, paid-up, irrevocable, worldwide license to publish or reproduce the published form of this work, or allow others to do so, for U.S. Government purposes.

\section{Definitions/Abbreviations}

CILCC - Composite International Truck Local and Commuter Cycle

DOE - U.S. Department of Energy

EPA - U.S. Environmental Protection Agency

FASTSim - Future Automotive System Technology Simulator

FC - fuel consumption

FE - fuel economy

HHDDT - Heavy Heavy-Duty Diesel Truck

mpg - miles per gallon

mph - miles per hour

NHTSA - National Highway Traffic Safety Administration

NREL - National Renewable Energy Laboratory

ReFUEL - Renewable Fuels and Lubricants

WVU City - West Virginia University City

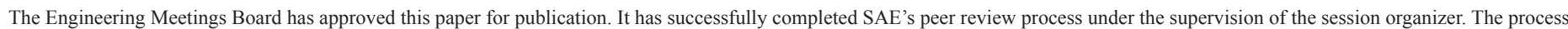
requires a minimum of three (3) reviews by industry experts.

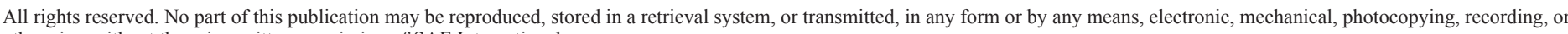
otherwise, without the prior written permission of SAE International.

Positions and opinions advanced in this paper are those of the author(s) and not necessarily those of SAE International. The author is solely responsible for the content of the paper.

ISSN 0148-7191

http://papers.sae.org/2015-01-2773 